“ (C) 2018 IEEE. Personal use of this material is permitted. Permission from IEEE must be obtained for all other uses, in any current or future media, including

reprinting/republishing this material for advertising or promotional purposes, creating new collective works, for resale or redistribution to servers or lists, or reuse of any copyrighted component of this work in other works." 


\title{
A Universal Multiple-Vector-Based Model Predictive Control of Induction Motor Drives
}

\author{
Yongchang Zhang, Member, IEEE, Yuning Bai and Haitao Yang, Student Member, IEEE
}

\begin{abstract}
Conventional finite control set-model predictive control (FCS-MPC) applies single voltage vector within each control period. This leads to relatively high steady state ripples and demand of fast sampling rate. Additionally, enumeration-based optimal vector selection is computationally intensive. Recently, double-vector-based schemes have been widely investigated to improve steady state performance of FCS-MPC. However, they are usually complicated in vector selection and duty ratio calculation. In this paper, a universal multiple-vector-based MPC (UMV-MPC) is proposed, which offers an efficient and flexible way to achieve the same performance as several existing methods. Unlike conventional FCS-MPC, enumerating process and state predictions for candidate voltage vectors are not required in the proposed UMV-MPC to select best voltage vectors. In UMVMPC, optimal vectors and duty ratios are directly constructed from deadbeat predictive control based on space vector modulation (SVM), providing a simple and effective method for vector selection and duty ratio optimization. Theoretical analysis as well as simulation and experimental tests on a $2.2 \mathrm{~kW}$ induction motor (IM) drive are demonstrated to validate the effectiveness of the proposed UMV-MPC.
\end{abstract}

Index Terms-Induction motor, model predictive control, double vector, deadbeat control

\section{INTRODUCTION}

FCS-MPC has become an attractive scheme in the control of power converters and motor drives [1]-[5]. Conventional FCSMPC applies single voltage vector during one control period [6]. As an inverter can only provide limited discrete voltage vectors, using only those basic vectors hardly satisfy control objectives. Hence, relatively high torque ripples and varying switching frequency can be observed when compared with control schemes using a modulator [7]-[9]. Additionally, fast sampling rate is generally required in FCS-MPC for satisfactory steady-state performance, imposing high computational burden on digital processor. To address these issues, many schemes have been proposed.

To improve steady performance of FCS-MPC without increasing sampling frequency, many schemes investigate employing two voltage vectors in one control period. Usually, an active voltage vector and a null vector are chosen in those methods [10]-[12]. The duty ratio of selected active voltage vector can be optimized to reduce torque ripple [10], minimize tracking error [11], etc. Results in these studies confirm better performance of applying two voltage vectors within one control period. However, restricting the second voltage vector as a null vector does not always lead to optimal performance. Hence, improved double-vector based MPCs relax this limitation to include two active voltage vectors [5], [8]. Performance are further improved especially at high speed region when the second voltage vector is not constrained. On the other hand, if common-mode voltage is one of the major concern, selected vectors should be restricted as two active voltage vectors [13]. Compared with conventional FCS-MPC, those double-vector based MPCs are more computational intensive due to additional calculation of vector's duty ratio and much more state predictions may need to be calculated [8].

Apart from performance improvement, there are also many methods were proposed to reduce complexity of FCS-MPC. Most schemes focus on how to simplify the process for vector selection without enumerating all available voltage vectors. The methods can be generally classified into two groups. The first group excludes undesired vectors based on some heuristic schemes. In [14], only three vectors need to be evaluated with cost function by considering the sign of torque or flux deviation. Similarly in [15], only part of available voltage vectors satisfying sliding-mode stable conditions are preselected and the others are excluded in the prediction process. To reduce switching frequency and prevent high voltage jump between two consecutive control periods, candidate vectors can also be preselected so that there is less than one switch change in each sampling period [16]. The other group is to reduce candidate vectors by finding sector distribution where the optimal voltage vector lies in. In [17], [18], reference voltage that forces cost function to be zero is calculated to find the sector which contains the optimal voltage vector. After finding the sector, only 2 or 3 voltage vectors are necessary for cost function evaluation. Hence, the computational load can be significantly reduced. Similarly, tracking error of predicted stator flux vector [19] and negative conjugate of complex power [1] can also be utilized to determine the sector which can refine the range of vector selection.

However, few research investigates simplifying the complexity of double-vector based MPCs, which can provide better steady-state performance. In [19] and [20], two vectors are selected as an active voltage vector and a zero vector. In both methods, the best active voltage vector can be fast determined without enumerating process for cost function minimization. As mentioned previously, the combination of active voltage vector and zero vector is not always the optimal choice. Hence, these methods need to be extended for more general application. Additionally, though the number of candidate vectors is reduced, state predictions are still required to minimize the cost function in some previous schemes [14], [17]. Namely, the best voltage vectors and their duty ratios can not be directly obtained with one step prediction. In this paper, the aforementioned issues will be addressed. A universal 
multiple-vector-based MPC (UMV-MPC) is proposed, which can directly determine the best voltage vectors and their corresponding duty ratios without any state prediction for discrete voltage vectors. With different configuration, two selected voltage vectors can be an active vector together with a zero vector or both active vectors. Furthermore, its equivalence with conventional enumeration based vector selection is validated by theoretical analysis. Hence, the control performance would not be compromised as the simplified scheme is exactly the same as the original algorithm.

The proposed UMV-MPC is based on deadbeat torque and flux control. Different from [17] and [18], which only apply single vector in one control period, the proposed method can achieve double-vector based MPC. Thus, better performance can be expected. Additionally, the process for vector selection is further simplified and complicated state predictions for candidate voltage vectors are completely avoided. It is found that if only tracking error is considered in the cost function, the optimal voltage vectors and their duty ratios can be directly reconstructed from DBPC based on SVM. Hence, the study shown in this paper not only introduces a low-complexity MPC method but also reveals its inherent relationship with DBPC under some circumstances. The effectiveness of the presented methods are validated by theoretical analysis, simulation and experimental tests on a IM drive platform.

\section{DynAmiC EQUATIONS OF IM}

\section{A. Dynamic Model of IM}

The dynamic equations of IM in an arbitrary reference frame can be expressed as [21]:

$$
\begin{aligned}
\boldsymbol{u}_{s} & =R_{s} \boldsymbol{i}_{s}+\frac{d \boldsymbol{\psi}_{s}}{d t}+j \omega_{k} \boldsymbol{\psi}_{s} \\
0 & =R_{r} \boldsymbol{i}_{r}+\frac{d \boldsymbol{\psi}_{r}}{d t}+j\left(\omega_{k}-\omega_{r}\right) \boldsymbol{\psi}_{r} \\
\boldsymbol{\psi}_{s} & =L_{s} \boldsymbol{i}_{s}+L_{m} \boldsymbol{i}_{r} \\
\boldsymbol{\psi}_{r} & =L_{m} \boldsymbol{i}_{s}+L_{r} \boldsymbol{i}_{r}
\end{aligned}
$$

where, $\omega_{k}$ is rotating speed of the reference frame; $\boldsymbol{u}_{s}$, $\boldsymbol{i}_{s}, \boldsymbol{i}_{r}, \boldsymbol{\psi}_{s}$ and $\boldsymbol{\psi}_{r}$ are the stator voltage, stator current, rotor current, stator flux linkage and rotor flux linkage vector, respectively; $R_{s}, R_{r}, L_{s}, L_{r}$ and $L_{m}$ are the stator resistance, rotor resistance, stator inductance, rotor inductance and mutual inductance, respectively; $\omega_{r}$ is the rotor speed.

In stationary reference frame $\left(\omega_{k}=0\right)$, the state space model of IM can be rearranged as [22]:

$$
\frac{d \boldsymbol{x}}{d t}=\boldsymbol{A} \boldsymbol{x}+\boldsymbol{B u}
$$

where $\boldsymbol{x}=\left[\begin{array}{cc}\boldsymbol{i}_{s} & \boldsymbol{\psi}_{s}\end{array}\right]^{T}$ are state variables; $\boldsymbol{u}=\boldsymbol{u}_{s}$ is the stator voltage vector and

$$
\begin{aligned}
\boldsymbol{A} & =\left[\begin{array}{cc}
-\lambda\left(R_{s} L_{r}+R_{r} L_{s}\right)+j \omega_{r} & \lambda\left(R_{r}-j L_{r} \omega_{r}\right) \\
-R_{s} & 0
\end{array}\right] \\
\boldsymbol{B} & =\left[\begin{array}{c}
\lambda L_{r} \\
1
\end{array}\right] \\
\lambda & =1 /\left(L_{s} L_{r}-L_{m}^{2}\right)
\end{aligned}
$$

In digital implementation, discretization of (5) is required to predict torque and flux for a given voltage vector. In this paper, the Heun's method [23], which can achieve higher accuracy than first-order Euler method, is employed to obtain discrete state space model of IM as following:

$$
\left\{\begin{array}{l}
\boldsymbol{x}_{p}^{k+1}=\boldsymbol{x}^{k}+T_{s c}\left(\boldsymbol{A} \boldsymbol{x}^{k}+\boldsymbol{B} \boldsymbol{u}_{s}^{k}\right) \\
\boldsymbol{x}^{k+1}=\boldsymbol{x}_{p}^{k+1}+\frac{T_{s c}}{2} \boldsymbol{A}\left(\boldsymbol{x}_{p}^{k+1}-\boldsymbol{x}^{k}\right)
\end{array}\right.
$$

where $T_{s c}$ is control period, $\boldsymbol{x}_{p}^{k+1}$ is predictor-corrector of state vector; $\boldsymbol{x}^{k+1}=\left[\begin{array}{ll}\boldsymbol{i}_{s}^{k+1} & \boldsymbol{\psi}_{s}^{k+1}\end{array}\right]^{T}$ is predicted vector of stator current and stator flux at $(k+1)$ th instant.

The rotor flux at $(k+1)$ th instant can be computed from predicted states $\boldsymbol{x}^{k+1}$ as:

$$
\boldsymbol{\psi}_{r}^{k+1}=\frac{L_{r}}{L_{m}} \boldsymbol{\psi}_{s}^{k+1}-\frac{1}{\lambda L_{m}} \boldsymbol{i}_{s}^{k+1},
$$

Then, the electromagnetic torque can be calculated as [24]:

$$
T_{e}^{k+1}=\frac{3}{2} N_{p} \lambda L_{m}\left(\boldsymbol{\psi}_{r}^{k+1} \otimes \boldsymbol{\psi}_{s}^{k+1}\right) .
$$

where, $\otimes$ represents cross product of two vectors and $N_{p}$ is the number of pole pairs.

\section{B. Flux Estimation}

To obtain the information of stator flux, a closed-loop full order observer is adopted in this paper. This kind of observer can achieve good accuracy over a wide speed range and presents good robustness against machine parameter variations. The mathematical model of the observer is expressed as [24]:

$$
\begin{gathered}
\frac{d \hat{\boldsymbol{x}}}{d t}=\boldsymbol{A} \hat{\boldsymbol{x}}+\boldsymbol{B} \boldsymbol{u}_{s}+\boldsymbol{G}\left(\boldsymbol{i}_{s}-\hat{\boldsymbol{i}}_{s}\right) . \\
\boldsymbol{G}=-\left[\begin{array}{c}
2 b \\
b /\left(\lambda L_{r}\right)
\end{array}\right],
\end{gathered}
$$

where $\hat{\boldsymbol{x}}=\left[\begin{array}{ll}\hat{\boldsymbol{i}}_{s} & \hat{\boldsymbol{\psi}}_{s}\end{array}\right]^{T}$ are estimated state variables including stator flux and stator current. A constant matrix $G$ is employed for better performance and $b$ is a negative constant [24]. More details about this observer can be found in [24] and not repeated here.

\section{Principle of the Proposed MPC}

Fig. 1 shows the control diagram of UMV-MPC. A PI controller is used to regulate rotor speed, from which the torque reference can be obtained. Stator flux is estimated by a full order observer which is demonstrated in Section II-B. Other details will be introduced in the following text.

\section{A. Deadbeat Control of Torque and Flux}

In [5], torque reference $T_{e}^{r e f}$ and flux magnitude reference $\psi^{\text {ref }}$ are equivalently converted into the reference of stator flux vector $\psi_{s}^{r e f}$. Then, a cost function only contains tracking error of stator flux vector as shown in (11) is minimized to select the best voltage vector.

$$
J=\left|\boldsymbol{\psi}_{s}^{r e f}-\boldsymbol{\psi}_{s}^{k+2}\right|
$$




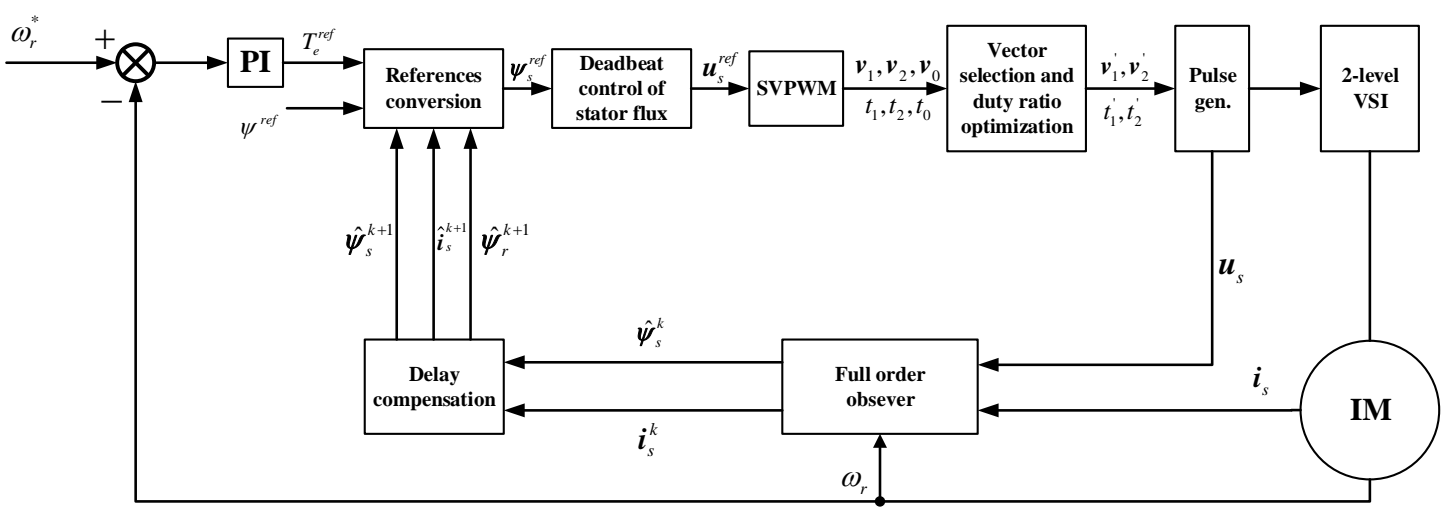

Fig. 1. Control diagram of the proposed MPTC.

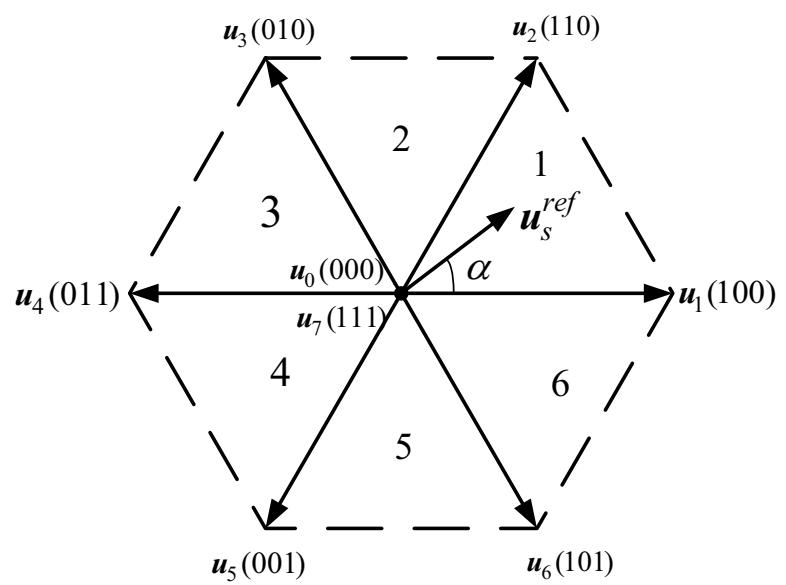

Fig. 2. Voltage vectors of a two-level inverter.

where flux error at $(k+2)$ th instant is evaluated in the cost function to compensate one-step delay in practical application. One merit of using cost function (11) is that weighting factor is not required to achieve simultaneous control of torque and flux magnitude [25]. Basic principle of obtaining $\boldsymbol{\psi}_{s}^{\text {ref }}$ can be summarized as follows.

1) Predicting stator current $\boldsymbol{i}_{s}^{k+1}$ and stator flux $\boldsymbol{\psi}_{s}^{k+1}$ according to discrete-time model (6).

2) Calculating rotor flux vector $\psi_{r}^{k+1}$ according to (7) with predicted $\boldsymbol{i}_{s}^{k+1}$ and $\boldsymbol{\psi}_{s}^{k+1}$. Then, rotor flux $\boldsymbol{\psi}_{r}^{k+2}$ can be predicted as

$\boldsymbol{\psi}_{r}^{k+2}=\boldsymbol{\psi}_{r}^{k+1}+T_{s c}\left[R_{r} \frac{L_{m}}{L_{r}} \boldsymbol{i}_{s}^{k+1}-\left(\frac{R_{r}}{L_{r}}-j \omega_{r}^{k}\right) \boldsymbol{\psi}_{r}^{k+1}\right]$

3) Converting $T_{e}^{r e f}$ and $\psi^{\text {ref }}$ into reference of stator flux vector $\boldsymbol{\psi}_{s}^{r e f}$ with predicted $\boldsymbol{\psi}_{r}^{k+2}$ as

$$
\begin{aligned}
\angle \boldsymbol{\psi}_{s}^{r e f} & =\angle \boldsymbol{\psi}_{r}^{k+2}+\arcsin \left(\frac{T_{e}^{r e f}}{\frac{3}{2} N_{p} \lambda L_{m}\left|\boldsymbol{\psi}_{r}^{k+2}\right| \psi^{r e f}}\right) \\
\boldsymbol{\psi}_{s}^{r e f} & =\psi^{r e f} e^{j \angle \boldsymbol{\psi}_{s}^{r e f}}
\end{aligned}
$$

After calculating stator flux vector $\boldsymbol{\psi}_{s}^{\text {ref }}$, deadbeat solution can be obtained by forcing stator flux to reach its reference at the end of next sampling period. From (1), the stator voltage vector reference in stationary frame $\left(\omega_{k}=0\right)$ can be derived as

$$
\boldsymbol{u}_{s}^{r e f}=R_{s} \boldsymbol{i}_{s}^{k+1}+\frac{\boldsymbol{\psi}_{s}^{r e f}-\boldsymbol{\psi}_{s}^{k+1}}{T_{s c}}
$$

For two-level inverter-fed IM drives, there are eight switching states (six active voltage vectors $\boldsymbol{u}_{1,2, \ldots, 6}$ and two null vectors $\boldsymbol{u}_{0,7}$ ), as shown in Fig. 2. Based on principle of space vector PWM (SVPWM), $\boldsymbol{u}_{s}^{\text {ref }}$ in sector $m(m=1,2 \ldots 6)$ can be synthesized by two adjacent active voltage vectors $\boldsymbol{u}_{m}, \boldsymbol{u}_{m+1}$ and a null vector $\boldsymbol{v}_{0}$ [26]. Additionally, vectors' duty cycles $d_{1}, d_{2}, d_{0}$ should satisfy the following equation:

$$
\boldsymbol{u}_{s}^{r e f}=\boldsymbol{u}_{m} d_{1}+\boldsymbol{u}_{m+1} d_{2}+\boldsymbol{v}_{0} d_{0}
$$

As a example shown in Fig. 2, if $\boldsymbol{u}_{s}^{\text {ref }}$ is located in sector 1, two active voltage vectos are $\boldsymbol{u}_{1}$ and $\boldsymbol{u}_{2}$. The duty ratios can be calculated as

$$
\begin{aligned}
& d_{1}=\frac{\sqrt{3}\left|\boldsymbol{u}_{s}^{r e f}\right|}{U_{d c}} \sin \left(60^{\circ}-\alpha\right) \\
& d_{2}=\frac{\sqrt{3}\left|\boldsymbol{u}_{s}^{r e f}\right|}{U_{d c}} \sin \alpha \\
& d_{0}=1-d_{1}-d_{2}
\end{aligned}
$$

where $\alpha$ is the angle between $\boldsymbol{u}_{s}^{\text {ref }}$ and $\boldsymbol{u}_{1} ; U_{d c}$ is DC link voltage.

$\boldsymbol{\psi}_{s}^{k+2}$ in cost function (11) can be calculated as

$$
\boldsymbol{\psi}_{s}^{k+2}=\boldsymbol{\psi}_{s}^{k+1}+T_{s c}\left(\boldsymbol{u}_{s}^{k+1}-R_{s} \boldsymbol{i}_{s}^{k+1}\right)
$$

According to (14) and (19), (11) can be rewritten as

$$
\begin{aligned}
J & =\left|\boldsymbol{\psi}_{s}^{r e f}-\boldsymbol{\psi}_{s}^{k+2}\right| \\
& =T_{s c}\left|\boldsymbol{u}_{s}^{r e f}-\boldsymbol{u}_{s}^{k+1}\right|
\end{aligned}
$$

From (20), it is clear that minimizing tracking error of stator flux is equivalent to minimizing voltage error. Based on this point, some tricks can be developed to determine the best voltage vector without enumerating process, which will be described in the following text. 


\section{B. Vector Selection and Duty Ratio Optimization}

After obtaining $\boldsymbol{u}_{s}^{r e f}$, SVPWM is normally used to synthesize the desired voltage. However, one [18], two [5] or three voltage vectors [27] can also be applied in one control period to minimize the tracking error. Many prior studies have applied two voltage vectors in one control period because of its satisfactory control performance [8], [28]-[30]. However, they are usually complicated in vector selction and duty ratio optimization. In the proposed UMV-MPC, the optimal vectors and duty ratios can be easily obtained without further state predictions after calculating $\boldsymbol{u}_{s}^{r e f}$. The detailed procedure is illustrated as follows.

Based on classic SVPWM [26], once $\boldsymbol{u}_{s}^{\text {ref }}$ is obtained, two adjacent active voltage vectors $\boldsymbol{u}_{m}, \boldsymbol{u}_{m+1}$ and a zero vector can be determined and their duty ratios can be calculated according to (16)-(18). The summation of each two duty cycles can be computed as:

$$
\left\{\begin{array}{l}
\text { sum }_{12}=d_{1}+d_{2} \\
\text { sum }_{01}=d_{0}+d_{1} \\
\text { sum }_{02}=d_{0}+d_{2}
\end{array}\right.
$$

After calculating sum 12 , sum 01 and $s_{02}$, the maximum one needs to be found. If $\operatorname{sum}_{12}$ is the maximum, two active vectors $\boldsymbol{u}_{m}, \boldsymbol{u}_{m+1}$ will be the best combination to minimize the cost function (20). Moreover, their duty cycles can be directly reconstructed as:

$$
\left\{\begin{array}{l}
d_{1}^{\prime}=d_{1}+0.5 d_{0} \\
d_{2}^{\prime}=d_{2}+0.5 d_{0}
\end{array}\right.
$$

Similarly, if sum $_{01}$ is the maximum, an active vector $\boldsymbol{u}_{m}$ and a zero vector $\boldsymbol{v}_{0}$ will be the best combination to minimize the cost function (20), and

$$
\left\{\begin{array}{l}
d_{1}^{\prime}=d_{1}+0.5 d_{2} \\
d_{0}^{\prime}=d_{0}+0.5 d_{2}
\end{array}\right.
$$

If sum $_{02}$ is the maximum, an active vector $\boldsymbol{u}_{m+1}$ and a zero vector $\boldsymbol{v}_{0}$ will be the best combination to minimize the cost function (20), and

$$
\left\{\begin{array}{l}
d_{2}^{\prime}=d_{2}+0.5 d_{1} \\
d_{0}^{\prime}=d_{0}+0.5 d_{1}
\end{array}\right.
$$

It can be seen that the vector selection and duty ratio optimization here are very simple. Neither state predictions for candidate voltage vectors nor evaluation of cost function is required. The validity of the proposed vector selection and duty ratio optimization will be analyzed in the next section.

\section{Switching Frequency Reduction}

To reduce switching frequency, if one of two vectors is a zero vector, $\boldsymbol{u}_{0}(000)$ or $\boldsymbol{u}_{7}(111)$ which produces less switching jumps is selected. For example, if $\boldsymbol{u}_{2}(110)$ and $\boldsymbol{u}_{0}(000)$ are determined as the optimal vectors, $\boldsymbol{u}_{0}(000)$ should be replaced by $\boldsymbol{u}_{7}(111)$. If switching frequency needs to be further reduced, vector sequences can be adjusted [28]. For example, if $\boldsymbol{u}_{3}(010)$ is applied till the end of the $k$ th control period,

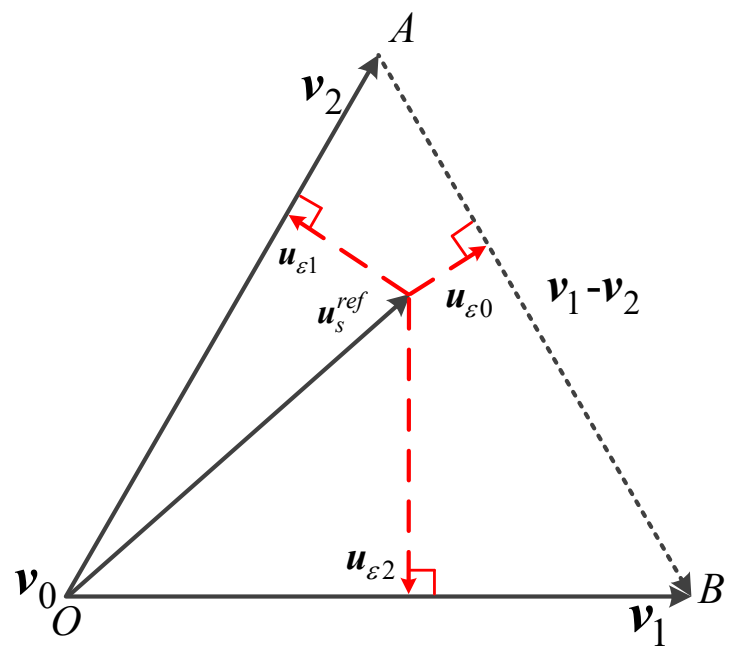

Fig. 3. Voltage error for different vector combinations.

and the vectors to be applied during $(k+1)$ th control period are $\boldsymbol{u}_{2}(110)$ and $\boldsymbol{u}_{3}(010)$, then $\boldsymbol{u}_{3}(010)$ instead of $\boldsymbol{u}_{2}(110)$ will be firstly applied to decrease switching transitions.

The above strategy does not change the dynamic behavior of UMV-MPC obviously, but may influence steady-state behavior. Comparative study will be carried out in Section VI-D.

\section{ANALYSIS OF UMV-MPC}

\section{A. Validity of Vector Selection and Duty Ratio Optimization}

In section III-B, detailed vector selection and duty ratio optimization for the proposed UMV-MPC have been introduced. In this section, theoretical analysis will be provided to confirm the validity of the proposed schemes. A equilateral triangle area $\triangle O A B$ made up of $\boldsymbol{v}_{1}, \boldsymbol{v}_{2}, \boldsymbol{v}_{0}$ is shown in Fig. 3. Due to symmetrical distribution of voltage vectors in a two-level inverter, the following analysis based on Fig. 3 is validated for all sectors shown in Fig. 2.

In Fig. $3, \boldsymbol{u}_{\varepsilon 0}, \boldsymbol{u}_{\varepsilon 1}$, and $\boldsymbol{u}_{\varepsilon 2}$ are minimum voltage errors resulting from vector combination $\left(\boldsymbol{v}_{1}, \boldsymbol{v}_{2}\right),\left(\boldsymbol{v}_{2}, \boldsymbol{v}_{0}\right)$ and $\left(\boldsymbol{v}_{1}, \boldsymbol{v}_{0}\right)$ respectively. As perpendicular distance from a point to a line is the shortest distance from a fixed point to any point on a fixed line, $\boldsymbol{u}_{\varepsilon 0}, \boldsymbol{u}_{\varepsilon 1}$ and $\boldsymbol{u}_{\varepsilon 2}$ are perpendicular to three sides of the triangle shown in Fig. 3.

For vector combination $\left(\boldsymbol{v}_{1}, \boldsymbol{v}_{2}\right)$, assuming the optimized duty ratios of $\boldsymbol{v}_{1}$ and $\boldsymbol{v}_{2}$ are $d_{v 1}$ and $d_{v 2}$ respectively, then the optimal voltage $\boldsymbol{u}_{\text {opt }}$ synthesized by $\left(\boldsymbol{v}_{1}, \boldsymbol{v}_{2}\right)$ is

$$
\begin{aligned}
\boldsymbol{u}_{o p t} & =d_{v 1} \boldsymbol{v}_{1}+d_{v 2} \boldsymbol{v}_{2} \\
& =d_{v 1} \boldsymbol{v}_{1}+\left(1-d_{v 1}\right) \boldsymbol{v}_{2}
\end{aligned}
$$

Additionally, $\boldsymbol{u}_{\varepsilon 0}$ can be synthesized by $\left(\boldsymbol{v}_{1}, \boldsymbol{v}_{2}\right)$ as

$$
\boldsymbol{u}_{\varepsilon 0}=k_{1} \boldsymbol{v}_{1}+k_{2} \boldsymbol{v}_{2}
$$

Considering $\boldsymbol{u}_{\varepsilon 0}$ is perpendicular to the side $A B$, the following equation holds

$$
\boldsymbol{u}_{\varepsilon 0} \odot\left(\boldsymbol{v}_{1}-\boldsymbol{v}_{2}\right)=0
$$

Based on (26) and (27), $k_{1}$ and $k_{2}$ can be solved as

$$
k_{1}=k_{2}
$$


As $\boldsymbol{u}_{\varepsilon 0}$ is the difference between $\boldsymbol{u}_{s}^{r e f}$ and $\boldsymbol{u}_{o p t}$, the following equations can be derived based on (15) and (25) as

$$
\begin{aligned}
\boldsymbol{u}_{\varepsilon 0} & =\boldsymbol{u}_{\text {opt }}-\boldsymbol{u}_{s}^{r e f} \\
& =\left(d_{v 1}-d_{1}\right) \boldsymbol{v}_{1}+\left(1-d_{v 1}-d_{2}\right) \boldsymbol{v}_{2}
\end{aligned}
$$

From (26), (28) and (30), the relationship between $d_{v 1}$ and $d_{1}$, $d_{2}$ can be obtained as:

$$
\begin{aligned}
d_{v 1} & =0.5\left(1+d_{1}-d_{2}\right) \\
& =d_{1}+0.5 d_{0}
\end{aligned}
$$

After obtaining $d_{v 1}, d_{v 2}$ can be derived as

$$
\begin{aligned}
d_{v 2} & =1-d_{v 1} \\
& =d_{2}+0.5 d_{0}
\end{aligned}
$$

Namely, $d_{v 1}$ and $d_{v 2}$ can be reconstructed as

$$
\left\{\begin{array}{l}
d_{v 1}=d_{1}+0.5 d_{0} \\
d_{v 2}=d_{2}+0.5 d_{0}
\end{array}\right.
$$

where, $d_{1}$ and $d_{2}$ are calculated with $\boldsymbol{u}_{s}^{r e f}$ based on SVPWM as shown in (16)-(18). From calculated $d_{v 1}$ and $d_{v 2}, \boldsymbol{u}_{\varepsilon 0}$ can be obtained according to (30) as

$$
\boldsymbol{u}_{\varepsilon 0}=0.5 d_{0}\left(\boldsymbol{v}_{1}+\boldsymbol{v}_{2}\right)
$$

Considering

$$
\begin{aligned}
\left|\boldsymbol{v}_{1}\right| & =\left|\boldsymbol{v}_{2}\right|=\frac{2}{3} U_{d c} \\
d_{0} & =1-d_{1}-d_{2}
\end{aligned}
$$

the amplitude of $\boldsymbol{u}_{\varepsilon 0}$ can be calculated as

$$
\left|\boldsymbol{u}_{\varepsilon 0}\right|=\left[1-\left(d_{1}+d_{2}\right)\right] \cdot \frac{\sqrt{3}}{3} U_{d c}
$$

Omitting tedious deduction process, the following equations can also be obtained in a similar way for vector combination $\left(\boldsymbol{v}_{1}, \boldsymbol{v}_{0}\right)$ as

$$
\begin{aligned}
\boldsymbol{u}_{\varepsilon 1} & =0.5 d_{2}\left(\boldsymbol{v}_{1}-2 \boldsymbol{v}_{2}\right) \\
\left|\boldsymbol{u}_{\varepsilon 1}\right| & =\left[1-\left(d_{1}+d_{0}\right)\right] \cdot \frac{\sqrt{3}}{3} U_{d c}
\end{aligned}
$$

And,

$$
\left\{\begin{array}{l}
d_{v 1}=d_{1}+0.5 d_{2} \\
d_{v 0}=d_{0}+0.5 d_{2}
\end{array}\right.
$$

Similarly, for vector combination $\left(\boldsymbol{v}_{2}, \boldsymbol{v}_{0}\right)$, the corresponding voltage error $\boldsymbol{u}_{\varepsilon 2}$ is

$$
\begin{aligned}
\boldsymbol{u}_{\varepsilon 2} & =0.5 d_{1}\left(\boldsymbol{v}_{2}-2 \boldsymbol{v}_{1}\right) \\
\left|\boldsymbol{u}_{\varepsilon 2}\right| & =\left[1-\left(d_{2}+d_{0}\right)\right] \cdot \frac{\sqrt{3}}{3} U_{d c}
\end{aligned}
$$

And,

$$
\left\{\begin{array}{l}
d_{v 2}=d_{2}+0.5 d_{1} \\
d_{v 0}=d_{0}+0.5 d_{1}
\end{array}\right.
$$

Comparing the result of voltage errors $\boldsymbol{u}_{\varepsilon 0}, \boldsymbol{u}_{\varepsilon 1}$, and $\boldsymbol{u}_{\varepsilon 2}$ shown in equations (37), (39) and (42), it is clear that the

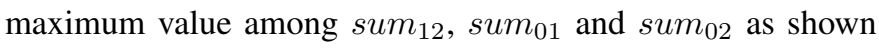

TABLE I

Optimal Vectors and DURATION TIME

\begin{tabular}{ccc}
\hline Maximum value & Optimal vectors & Optimal duty cycles \\
\hline sum $_{12}$ & $\left(\boldsymbol{v}_{1}, \boldsymbol{v}_{2}\right)$ & $d_{1}+0.5 d_{0}, d_{2}+0.5 d_{0}$ \\
sum $_{01}$ & $\left(\boldsymbol{v}_{1}, \boldsymbol{v}_{0}\right)$ & $d_{1}+0.5 d_{2}, d_{0}+0.5 d_{2}$ \\
sum $_{02}$ & $\left(\boldsymbol{v}_{2}, \boldsymbol{v}_{0}\right)$ & $d_{2}+0.5 d_{1}, d_{0}+0.5 d_{1}$ \\
\hline
\end{tabular}

TABLE II

VECTOR SELECTION FOR SINGLE-VECTOR FCS-MPC

\begin{tabular}{ccc}
\hline Maximum value & Optimal vectors & Duty ratio \\
\hline$d_{1}$ & $\boldsymbol{v}_{1}$ & 1 \\
$d_{2}$ & $\boldsymbol{v}_{2}$ & 1 \\
$d_{0}$ & $\boldsymbol{v}_{0}$ & 1 \\
\hline
\end{tabular}

TABLE III

VECTOR SELECTION FOR DUTY-MPC

\begin{tabular}{ccc}
\hline Maximum value & Optimal vectors & Optimal duty cycles \\
\hline sum $_{01}$ & $\left(\boldsymbol{v}_{1}, \boldsymbol{v}_{0}\right)$ & $d_{1}+0.5 d_{2}, d_{0}+0.5 d_{2}$ \\
sum $_{02}$ & $\left(\boldsymbol{v}_{2}, \boldsymbol{v}_{0}\right)$ & $d_{2}+0.5 d_{1}, d_{0}+0.5 d_{1}$ \\
\hline
\end{tabular}

in (21) leads to minimum tracking error of voltage. Hence, the vector selection method based on comparing the summation of duty cycles presented in section III-B can accurately pick out two best voltage vectors. Additionally, duty ratios calculated in (22), (40) and (43) are in accordance with theoretical results shown in (33), (40) and (43). The proposed method can be summarized in Table I. As shown in Fig. 2, $\boldsymbol{v}_{1}$ and $\boldsymbol{v}_{2}$ represents $\boldsymbol{u}_{m}$ and $\boldsymbol{u}_{m+1}$ when $\boldsymbol{u}_{s}^{r e f}$ is located in sector $m$. $\boldsymbol{v}_{0}$ is a null vector, which should be selected between $\boldsymbol{u}_{0}$ and $\boldsymbol{u}_{7}$ to avoid high switching jumps, as stated in section III-C.

\section{B. Relationship and Comparison With Other MPCs}

For single-vector based FCS-MPC [25], [31], it is only required to find the maximum duty ratio among $d_{1}, d_{2}, d_{0}$. The voltage vector corresponding to maximum duty ratio is the best one minimizing cost function (20). The method for single vector selection is summarized in Table II. As only one step prediction with some logical operation are required to determine the best voltage vector, the proposed scheme is much simpler compared with methods based on enumerating process with state predictions for all candidate vectors.

In [10], [11], [19] and [20], two vectors are constrained as an active voltage vector and a zero vector. For convenience, such methods are named as Duty-MPC in the following text. For Duty-MPC, only sum s1 $_{1}$ and sum $_{02}$ needs to be compared to determine whether $\left(\boldsymbol{v}_{1}, \boldsymbol{v}_{0}\right)$ or $\left(\boldsymbol{v}_{2}, \boldsymbol{v}_{0}\right)$ is the best vector combination. This strategy can be concluded in Table II. To further improve the performance, combinations of two active voltage vectors are also allowed in [5] and [8]. The vector selection and duty ratio optimization for those methods have been presented in Table I. Certainly, the desired voltage can also be synthesized by modulation algorithm such as SVPWM after obtaining $\boldsymbol{u}_{s}^{\text {ref }}$, as shown in [32]. In this case, it is the same as a deadbeat predictive control method. 
TABLE IV

MACHINE AND CONTROL PARAMETERS

\begin{tabular}{lcr}
\hline DC-bus voltage & $U_{d c}$ & $540 \mathrm{~V}$ \\
Rated power & $P_{N}$ & $2.2 \mathrm{~kW}$ \\
Rated voltage & $U_{N}$ & $380 \mathrm{~V}$ \\
Rated frequency & $f_{N}$ & $50 \mathrm{~Hz}$ \\
Rated torque & $T_{N}$ & $14 \mathrm{Nm}$ \\
Number of pole pairs & $N_{p}$ & 2 \\
Stator resistance & $R_{s}$ & $3.065 \Omega$ \\
Rotor resistance & $R_{r}$ & $1.879 \Omega$ \\
Mutual inductance & $L_{m}$ & $0.232 \mathrm{H}$ \\
Stator inductance & $L_{s}$ & $0.242 \mathrm{H}$ \\
Rotor inductance & $L_{r}$ & $0.242 \mathrm{H}$ \\
Sampling frequency & $f s$ & $15 \mathrm{kHz}$ \\
Flux amplitude reference & $\left|\psi_{s}^{*}\right|$ & $0.85 \mathrm{~Wb}$ \\
\hline
\end{tabular}

As mentioned previously, conventional double-vector based MPCs are complicate in selecting vectors and calculating duty ratios. High computational effort is generally required for state predictions to evaluate the influence of candidate vectors on control performance. By comparison, the proposed UMV-MPC can quickly pick out best vectors and optimize their duty ratios based on classic SVM. Both complicate enumerating process for vector selection and high computational effort for calculating optimal duration of selected vectors are eliminated. What's more, by different configuration as mentioned above, the proposed UMV-MPC can simply achieve different predictive control schemes, such as single-vector based MPC [25], [31], Duty-MPC [10], [11], generalized double-vector based MPC [5], [8] and deadbeat predictive control [32]. All these control methods are unified into one control frame, providing a flexible and simple method for achieving different control schemes.

\section{Simulation Study}

In this section, the effectiveness of the proposed MPC is evaluated in the environment of MATLAB/Simulink. Specifically, the performance of UMV-MPC is compared with doublevector based MPC presented in [5], which is refereed as prior-MPC in the following text. In all the following tests, the strategy of vector-selection and duty ratio optimization as shown in Table I is adopted in UMV-MPC. For both UMVMPC and prior-MPC, the vector sequence is dynamically adjusted to reduce the switching frequency, as described in section III-C. The control diagram of UMV-MPC is shown in Fig. 1, and the parameters of machine and control system are listed in Table IV.

Fig. 4 shows responses of rotor speed, electromagnetic torque, stator flux amplitude, and one-phase current when the machine starts from standstill to $1500 \mathrm{r} / \mathrm{min}$. An external load of $14 \mathrm{Nm}$ is suddenly applied at $t=0.2 \mathrm{~s}$. To provide sufficient torque during startup without large current, the scheme of preexcitation based on dc chopping is employed [24]. After preexcitation, it can be seen that the motor accelerates quickly to $1500 \mathrm{r} / \mathrm{min}$. After applying external load, the output torque increases quickly and the rotor speed restores to $1500 \mathrm{r} / \mathrm{min}$. The responses of two methods are the same, which can be further confirmed by comparing selected vectors, as shown in Fig. 5.

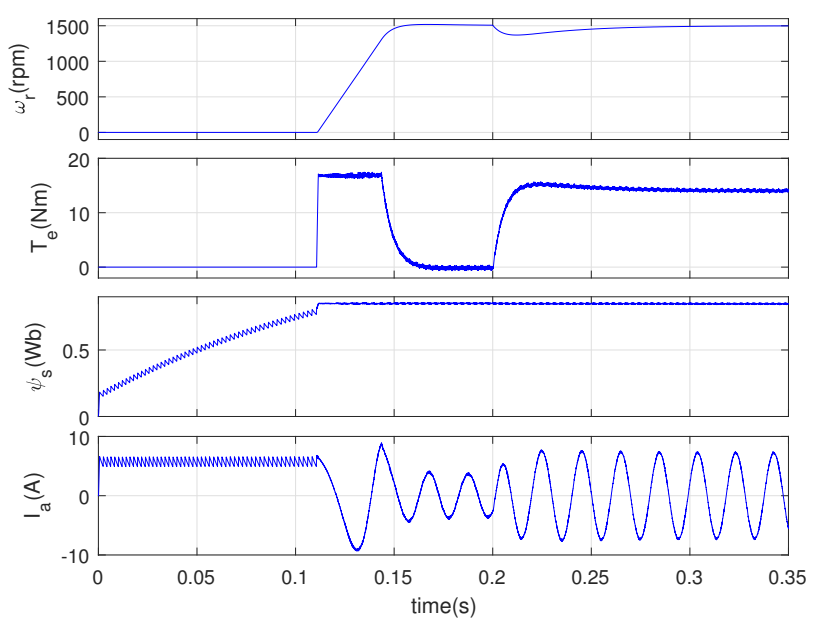

(a)

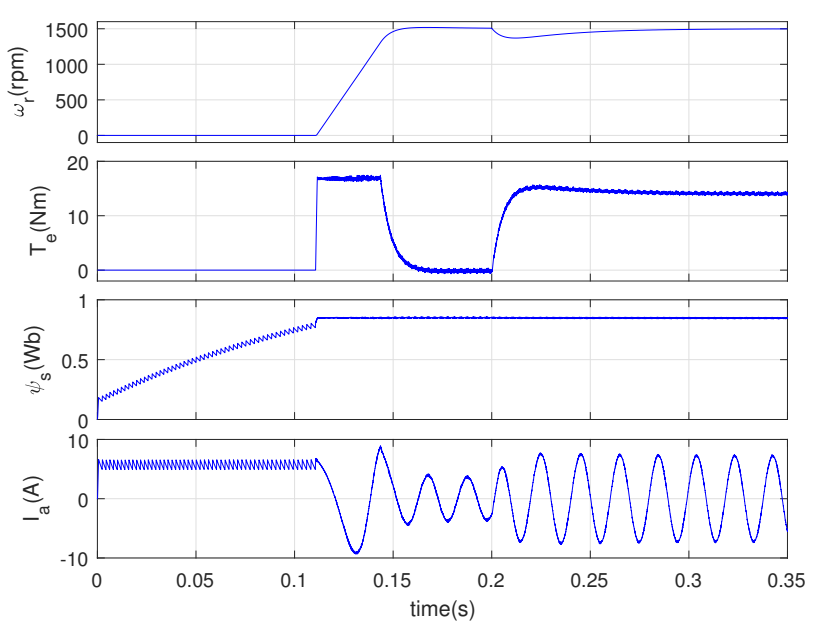

(b)

Fig. 4. Simulated starting responses from standstill to $1500 \mathrm{r} / \mathrm{min}$ with sudden load change at $0.2 \mathrm{~s}$ for (a) prior-MPC, (b) UMV-MPC.

Fig. 5a shows the selected two vectors for both methods when the machine starts from zero to $1500 \mathrm{r} / \mathrm{min}$, corresponding to the time range of $0.1-0.18 \mathrm{~s}$ in Fig. 4 . While Fig. $5 \mathrm{~b}$ shows the selected two vectors when the external load is applied, corresponding to the time range of $0.18 \mathrm{~s}-0.26 \mathrm{~s}$ in Fig. 4. It should be noted that two zero vectors $\boldsymbol{u}_{0}(000)$ and $\boldsymbol{u}_{7}(111)$ are both numbered as 0 in the figure. It can be found in Fig. 5 that selected two vectors in prior-MPC and UMVMPC are exactly the same. However, best two voltage vectors are selected in prior-MPC by minimizing cost function based on predicting state variables for all feasible voltage vectors, which is much more complex than the proposed UMV-MPC. This tests confirm that the proposed UMV-MPC can select exactly the same best vectors as conventional enumerating based schemes.

\section{EXPERIMENTAL RESULTS}

\section{A. Experimental Setup}

The proposed UMV-MPC is also experimentally tested on a two-level inverter-fed IM drive platform, which uses a 32bit floating point DSP TMS320F28335 to accomplish the 

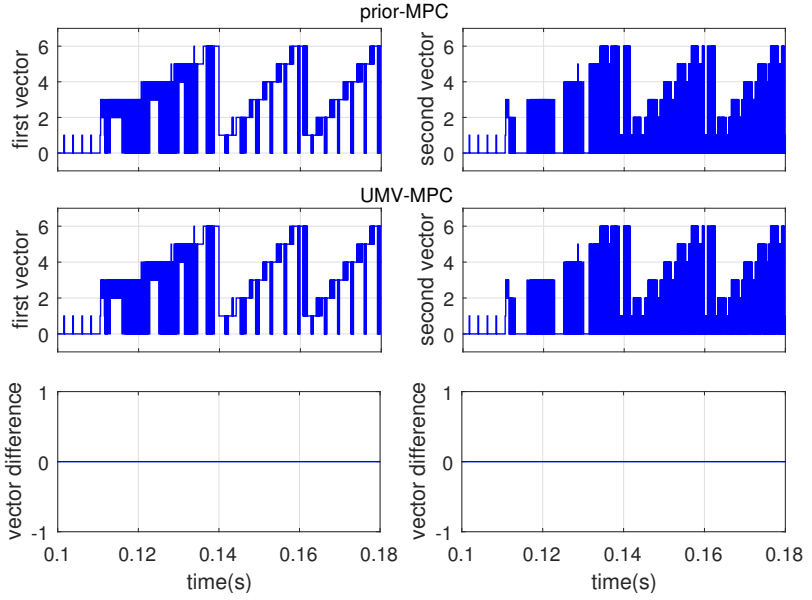

(a)
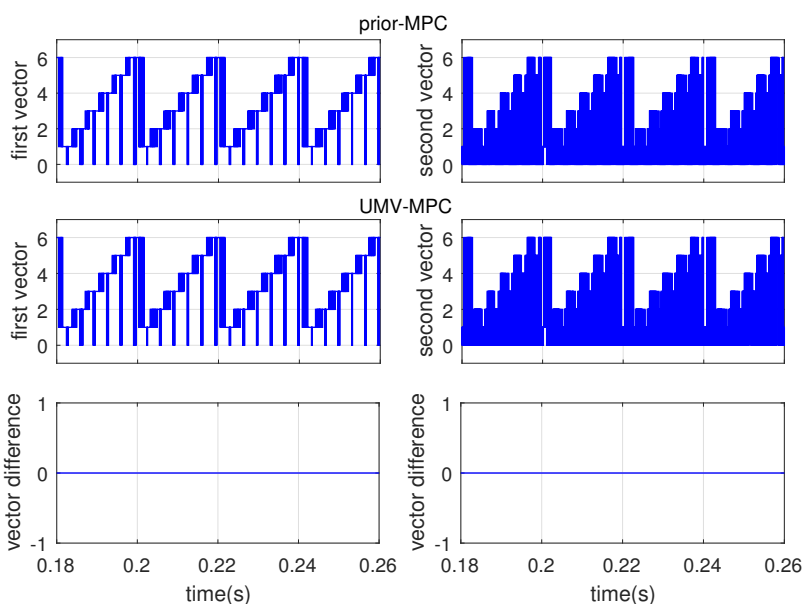

(b)

Fig. 5. Selected two vectors for prior-MPC and UMV-MPC in simulation. (a) during accelerating process and (b) during sudden load change.

developed control algorithm. The test rig is illustrated in Fig. 6. The parameters of motor and control system have been presented in Table IV. In all testing results, the value of concerned variables are obtained via a onboard DA converter except stator current, which is directly measured by a current probe. All data is acquired by a ScopeCoder DL850 and then transferred to PC for analysis.

\section{B. Investigation of Dynamic Performance and Comparison With Prior-MPC}

To further validate that UMV-MPC is equivalent with priorMPC, experimental results of the machine starts from zero to $1500 \mathrm{r} / \mathrm{min}$ are presented in Fig. 7. Similar to the simulation results shown in section $\mathrm{V}$, it is seen that for both methods, rotor speed can quickly accelerates to the reference. And, stator flux magnitude can be well kept as constant despite of variation of speed and torque. The difference between two methods is very insignificant.

Fig. 8 shows the responses during speed reversal at rated speed. It is clear that both methods can achieve smooth transition across zero speed, showing good performance over a wide speed range. The amplitude of stator flux is constant

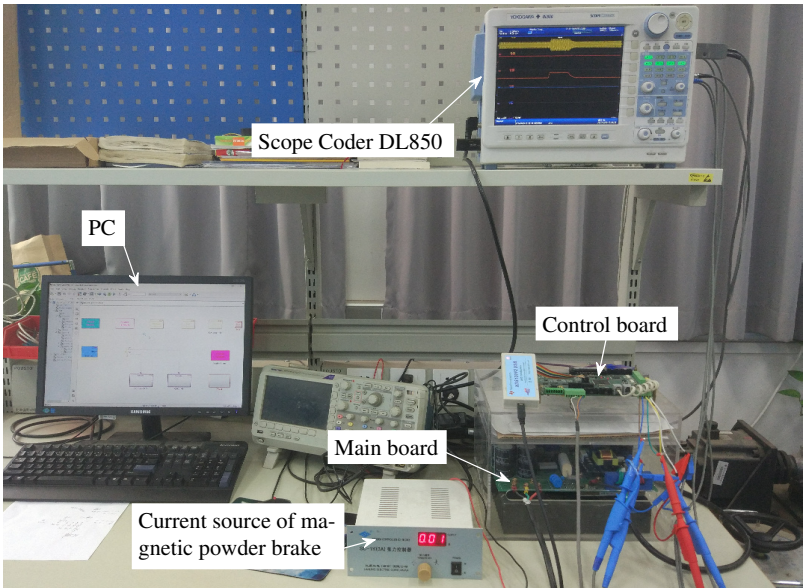

(a)

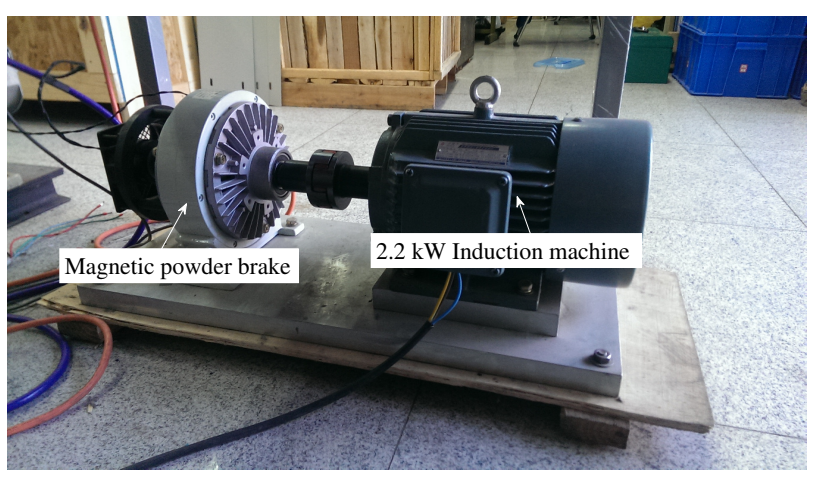

(b)

Fig. 6. Experimental setup of two-level inverter-fed IM drive. (a) inverter and oscilloscope, (b) 2.2-kW IM and magnetic powder brake.

during the whole dynamic process, indicating that decoupled control of stator flux and torque is well achieved. Again, there is no obvious difference between prior-MPC and UMV-MPC. Therefore, experimental tests can justify that UMV-MPC is equivalent with prior-MPC, which has also been supported by theoretical analysis and simulation tests in previous sections.

\section{Investigation of Steady-State Performance for different $M P C s$}

The equivalence between UMV-MPC and prior-MPC has been proved in previous chapters. Hence, experimental results of prior-MPC are no longer given in subsequent sections. Additionally, UMV-MPC which removes switching frequency reduction strategy as stated in section III-C is tested. For simplicity, it is named as UMV-MPC2 in the following text. Furthermore, the Duty-MPC which constrains vector combination as an active vector and a zero vector is implemented. For Duty-MPC, the principle of vector selection and duty ratio optimization has been summarized in Table III.

Fig. 9 presents the responses of high-speed operation at $1500 \mathrm{r} / \mathrm{min}$ without load for Duty-MPC, UMV-MPC and UMV-MPC2. For all of three methods, rotor speed can be well controlled at the reference. The current waveforms are sinusoidal. For each method, the torque ripple is 0.3610 $\mathrm{Nm}, 0.3297 \mathrm{Nm}$ and $0.3384 \mathrm{Nm}$ respectively. Total harmonic distortion (THD) of stator current is calculated and presented 


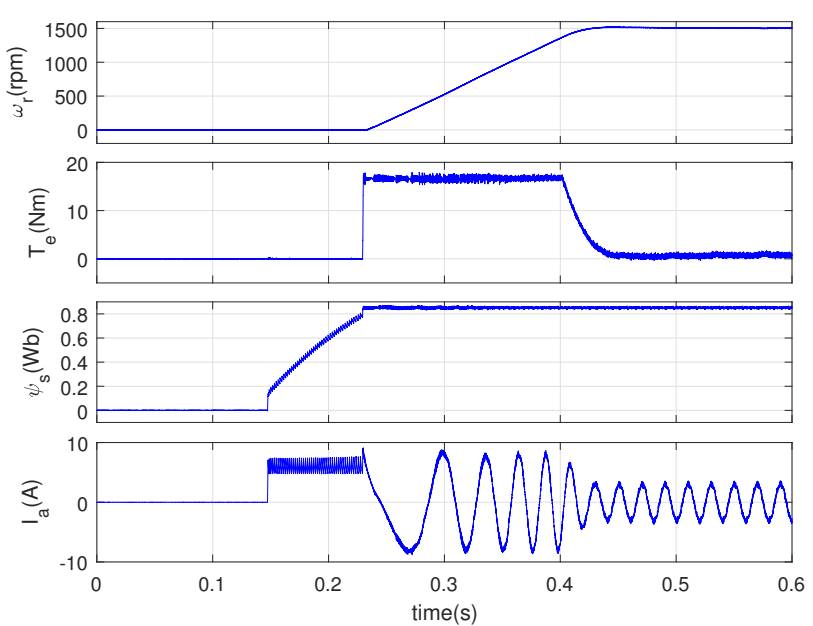

(a)
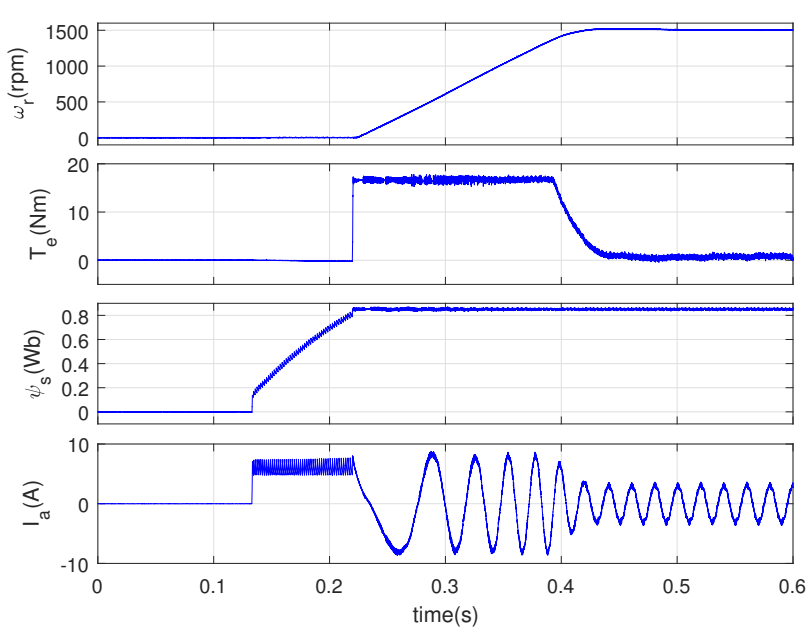

(b)

Fig. 7. Starting from standstill to $1500 \mathrm{r} / \mathrm{min}$ for (a) prior-MPC, (b) UMVMPC.

in Fig. 10. Unlike Duty-MPC, vector combinations of two active vectors are not excluded in UMV-MPC and UMVMPC2. Hence, UMV-MPC and UMV-MPC2 can select best two voltage vectors in a broader range, resulting in better steady-state performance. From test results, it can be found that both current THD and torque ripple are reduced in UMVMPC and UMV-MPC2 when compared with Duty-MPC.

\section{Quantitative Comparison for Different MPCs}

Numerical comparisons of current THD and torque ripple for different MPC methods at various speeds are shown in Figs. 11 and 12 respectively. It is seen that UMV-MPC2 has best performance during low and mid speed ranges and presents similar performance with UMV-MPC at high speeds. This indicates that switching frequency reduction strategy as mentioned in section III-C would influence steady-state performance during low and mid speed ranges.

Meanwhile, the performance of Duty-MPC and UMV-MPC are similar in low and mid speed ranges. The reason is that the vector combinations selected by both methods are a nonzero vector and a zero vector in most cases in this speed range [8]. However, the performance of Duty-MPC becomes worse
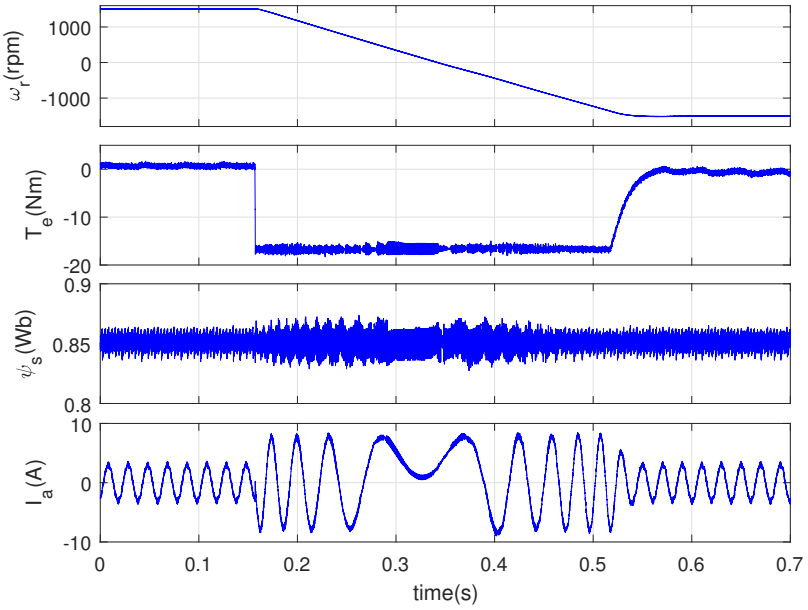

(a)

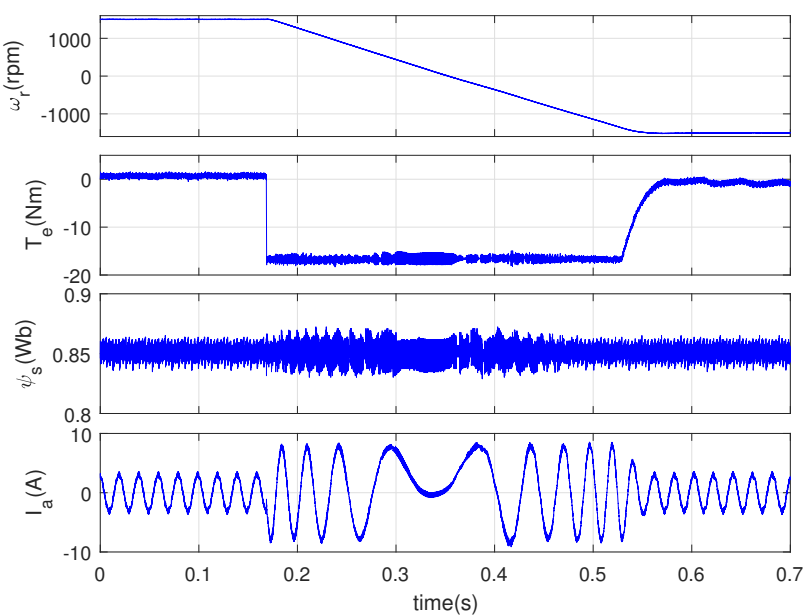

(b)

Fig. 8. Responses during speed reversal at $1500 \mathrm{r} / \mathrm{min}$ for (a) prior-MPC, (b) UMV-MPC.

at high speeds where the best second voltage vector is usually not a zero vector.

The average switching frequencies of different methods are also investigated, as shown in Fig. 13. Since both Duty-MPC and UMV-MPC adjust vector sequence to reduce switching frequency, their switching frequencies are lower than that of UMV-MPC2. When rated load is applied during high speed operation, as shown in Fig. 13b, the average switching frequency of Duty-MPC drops significantly. This is mainly because the optimal second voltage vector is not a zero vector at high speeds. In this circumstance, the optimal duty ratio of selected active voltage vector is usually calculated as 1 . This is equivalent to applying single voltage vector in one control period. Hence, switching jumps become smaller for Duty-MPC. In contrast, UMV-MPC and UMV-MPC2 can always pick out two optimal voltage vectors. As a result, they outperforms Duty-MPC at high speed range.

\section{E. Investigation of Performance at Low Speed Operation}

Finally, to validate the effectiveness of UMV-MPC at very low speed, the steady-state responses at $3 \mathrm{r} / \mathrm{min}$ without and with $90 \%$ rated load are demonstrated in Fig. 14. It is seen that 


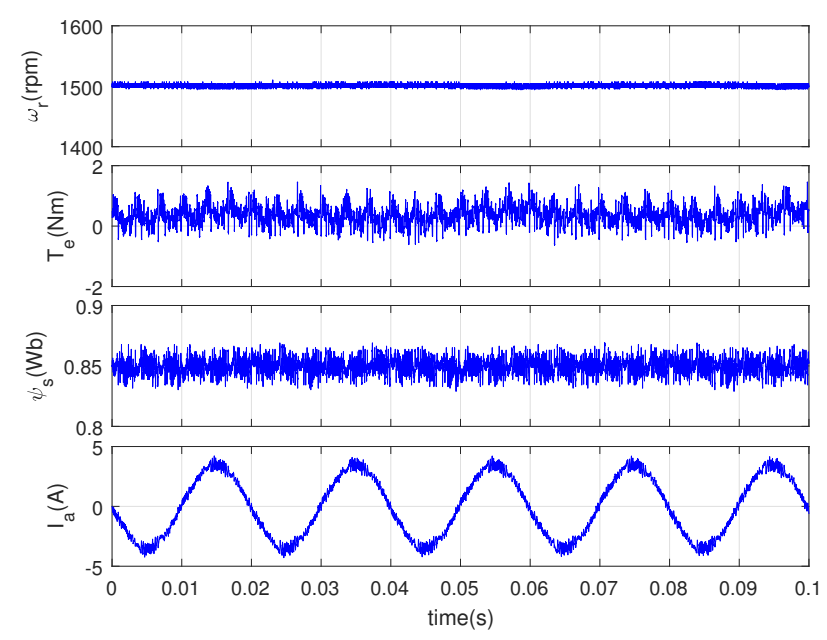

(a)

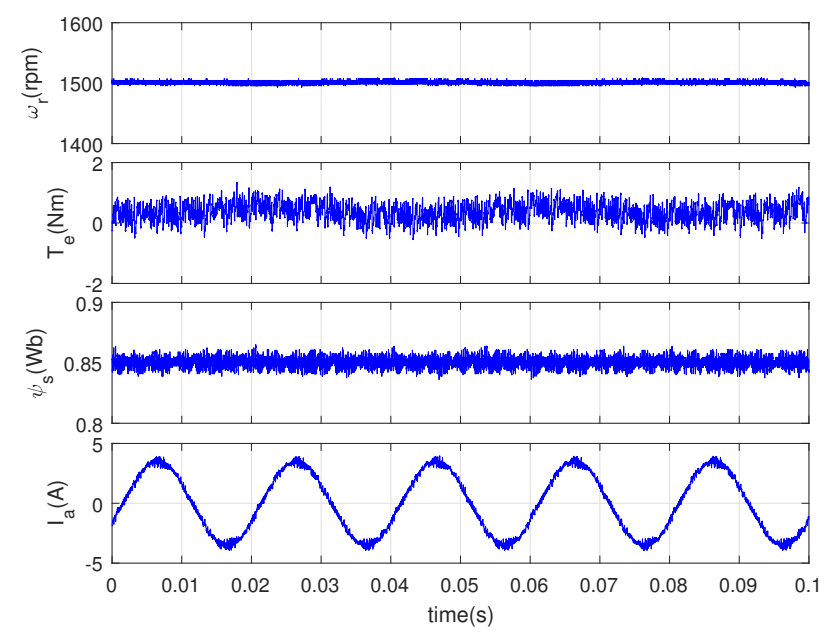

(b)

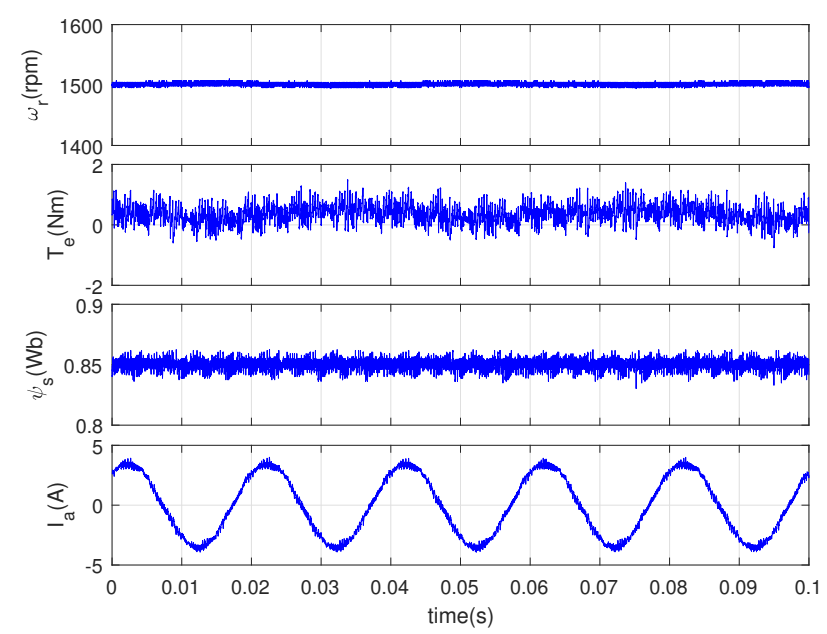

(c)

Fig. 9. High-speed operation at $1500 \mathrm{r} / \mathrm{min}$ without load for (a) Duty-MPC, (b) UMV-MPC, (c) UMV-MPC2.

the proposed UMV-MPC can keep its good performance even at extremely low speed. Due to poor stability of external load provided by the magnetic powder brake, some fluctuations can be observed in the rotor speed when load is applied. Nevertheless, the magnitude of stator flux is constant and the
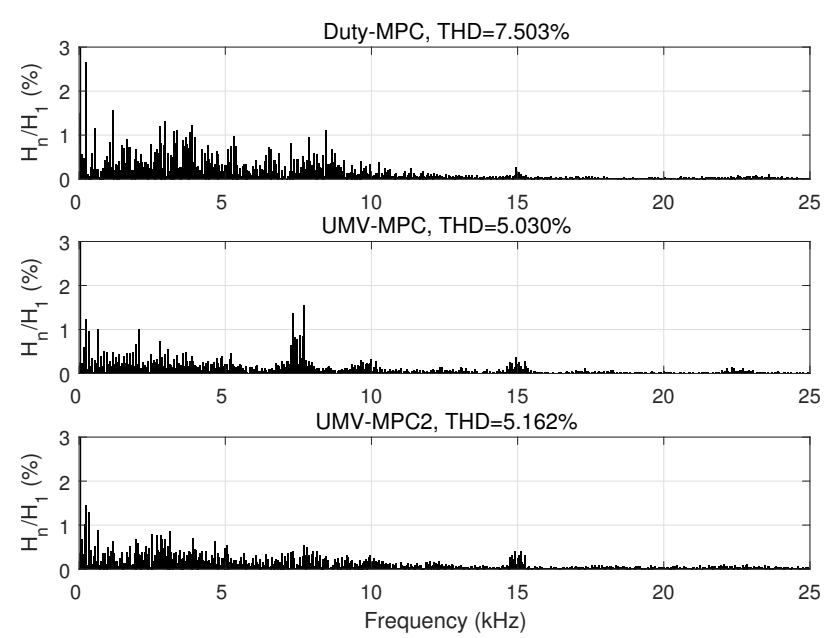

Fig. 10. Harmonic spectrum of stator current for Duty-MPC, UMV-MPC and UMV-MPC2 at $1500 \mathrm{r} / \mathrm{min}$ without load.

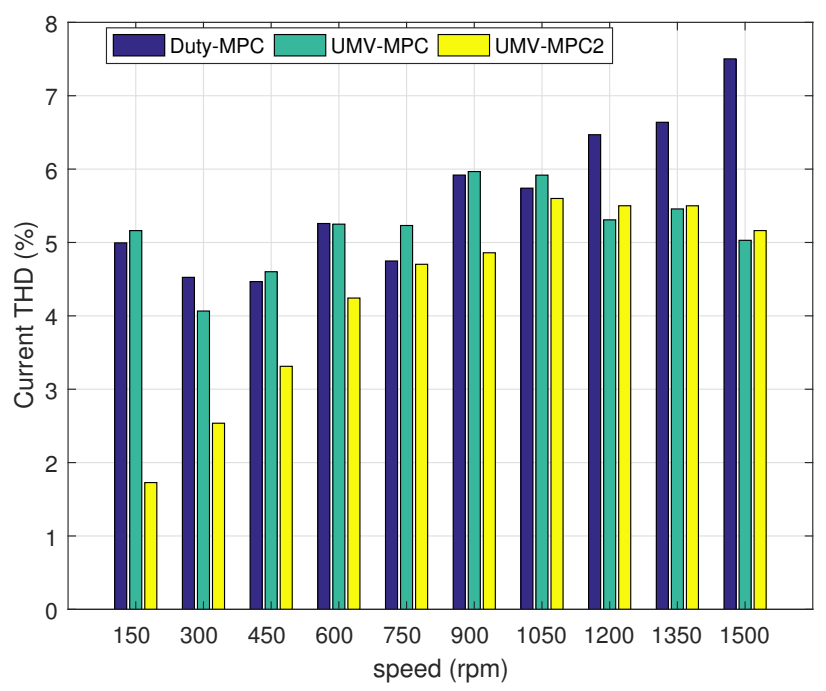

Fig. 11. Comparisons of current THD for Duty-MPC, UMV-MPC and UMVMPC2, operating at different speeds without load.

current waveform is sinusoidal. This test confirms that stable control with good performance can be achieved at very low speed for UMV-MPC.

\section{CONCLUSION}

In this paper, a universal multiple-vector-based MPC is proposed and verified by simulation and experimental tests. Compared with conventional multiple-vector based MPCs, UMV-MPC is more efficient in vector selection and duty ratio optimization when only tracking error is considered in the cost function. What's more, the UMV-MPC can be flexibly adjusted to achieve different MPC schemes, providing a unified control frame to test and compare different control methods. From the basic principle of UMV-MPC, it can be found that the only difference between UMV-MPC and conventional deadbeat control exists in the modulation stage. In UMV-MPC, two vectors are applied to minimize the error between synthesized voltage and reference voltage. While in deadbeat control, a modulator is directly used to synthesize reference voltage. 


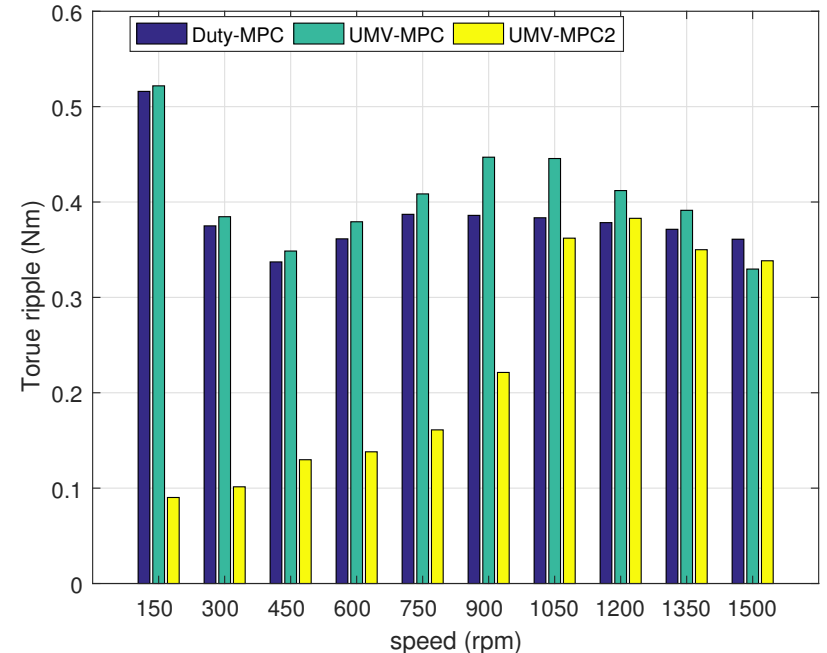

(a)

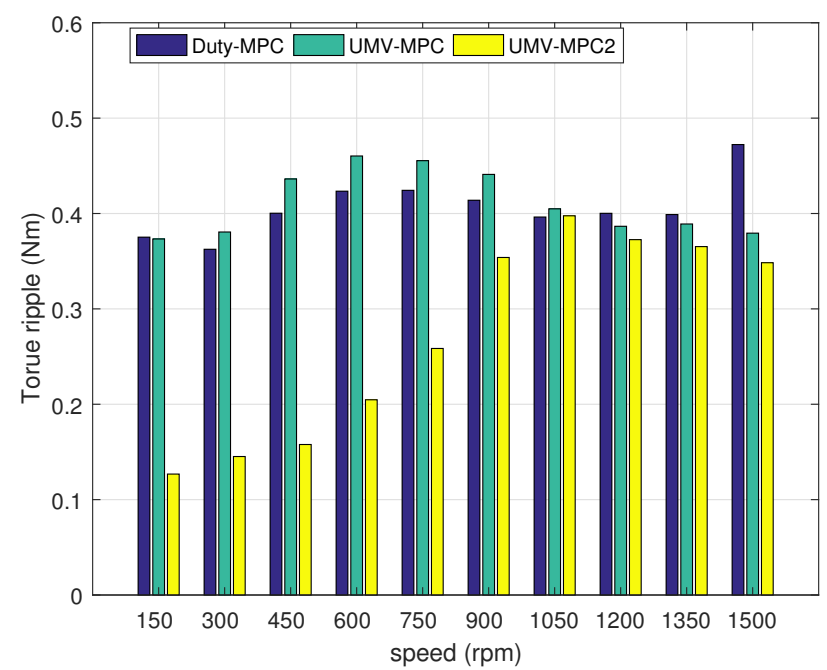

(b)

Fig. 12. Comparisons of torque ripple for Duty-MPC, UMV-MPC and UMVMPC2 at different speeds. (a) Without load and (b) with rated load.

From simulation and experimental tests, UMV-MPC is equivalent to conventional enumerating process based MPCs. Test results validate that UMV-MPC works well over a wide speed range during both dynamic and steady-state process. Stable control with satisfactory performance can be achieved even at very low speed. Comparative studies, tests under dynamic and steady-state operation, and average switching frequency are intensively investigated to confirm the effectiveness of UMV-MPC.

\section{REFERENCES}

[1] Y. Zhang and W. Xie, "Low complexity model predictive control-single vector-based approach," IEEE Trans. Power Electron., vol. 29, no. 10, pp. 5532-5541, Oct 2014.

[2] B. S. Riar, J. Scoltock, and U. K. Madawala, "Model predictive direct slope control for power converters," IEEE Trans. Power Electron., vol. 32, no. 3, pp. 2278-2289, March 2017.

[3] M. Habibullah, D. D. C. Lu, D. Xiao, and M. F. Rahman, "Finite-state predictive torque control of induction motor supplied from a three-level npc voltage source inverter," IEEE Trans. Power Electron., vol. 32, no. 1, pp. 479-489, Jan 2017.

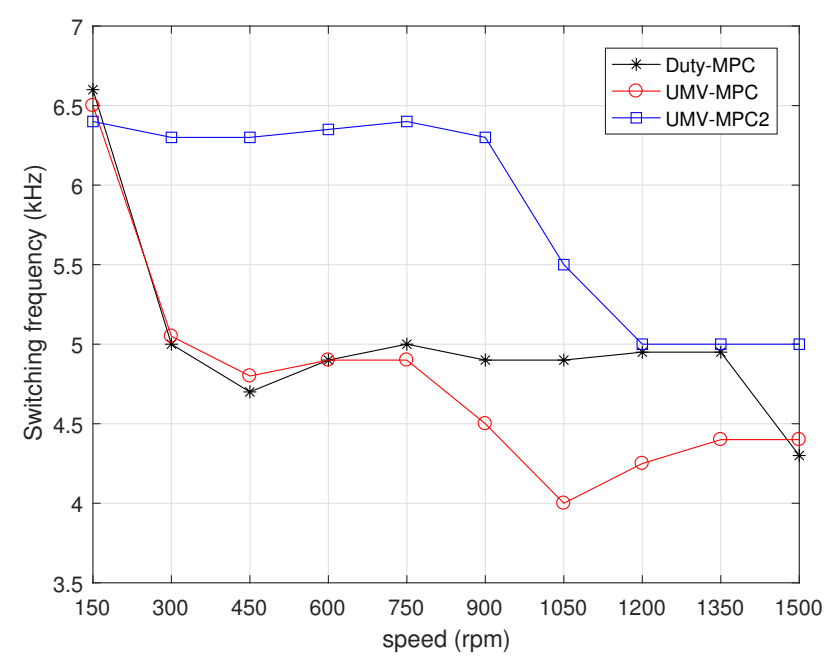

(a)

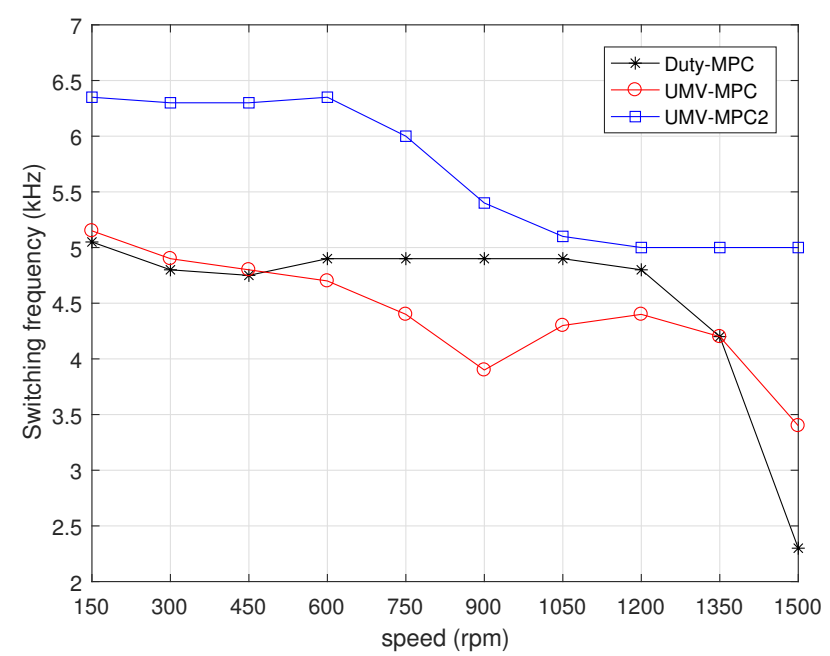

(b)

Fig. 13. Average switching frequencies for Duty-MPC (marked with “*”), UMV-MPC (marked with "O") and UMV-MPC2 (marked with “ $\square$ ”) at different speeds. (a) Without load and (b) with rated load.

[4] C. Martín, M. R. Arahal, F. Barrero, and M. J. DurÃąn, "Five-phase induction motor rotor current observer for finite control set model predictive control of stator current," IEEE Trans. Ind. Electron., vol. 63, no. 7, pp. 4527-4538, July 2016.

[5] Y. Zhang and H. Yang, "Two-vector-based model predictive torque control without weighting factors for induction motor drives," IEEE Trans. Power Electron., vol. 31, no. 2, pp. 1381-1390, Feb 2016.

[6] J. Rodriguez and P. Cortes, Predictive control of power converters and electrical drives. Wiley-IEEE Press, 2012, vol. 37.

[7] J. Rodriguez, R. Kennel, J. Espinoza, M. Trincado, C. Silva, and C. Rojas, "High-performance control strategies for electrical drives: An experimental assessment," IEEE Trans. Ind. Electron., vol. 59, no. 2, pp. $812-820$, feb. 2012.

[8] Y. Zhang and H. Yang, "Generalized two-vector-based model-predictive torque control of induction motor drives," IEEE Trans. Power Electron. vol. 30, no. 7, pp. 3818-3829, July 2015.

[9] M. H. Vafaie, B. M. Dehkordi, P. Moallem, and A. Kiyoumarsi, "A new predictive direct torque control method for improving both steadystate and transient-state operations of the pmsm," IEEE Trans. Power Electron., vol. 31, no. 5, pp. 3738-3753, May 2016.

[10] S. Davari, D. Khaburi, and R. Kennel, "An improved fcs-mpc algorithm for an induction motor with an imposed optimized weighting factor," IEEE Trans. Power Electron., vol. 27, no. 3, pp. 1540 -1551, march 2012.

[11] Y. Zhang and H. Yang, "Model predictive torque control of induction motor drives with optimal duty cycle control," IEEE Trans. Power 


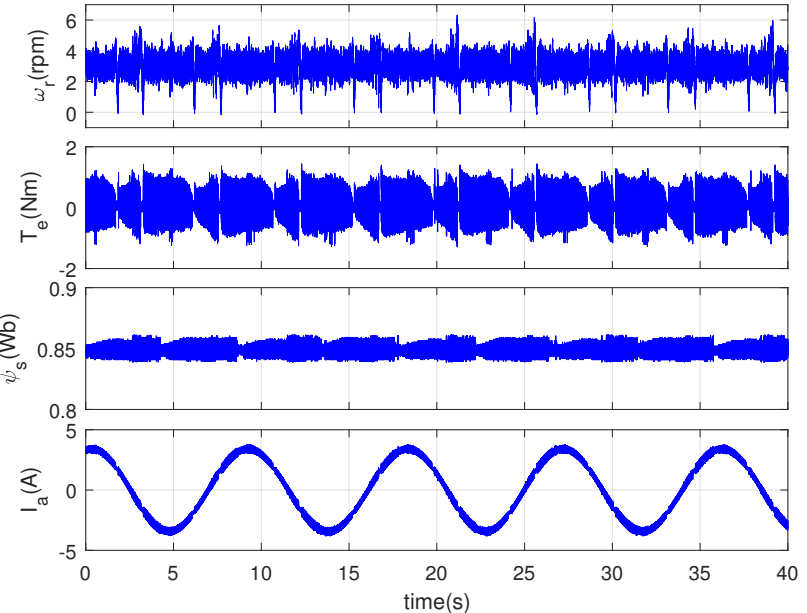

(a)
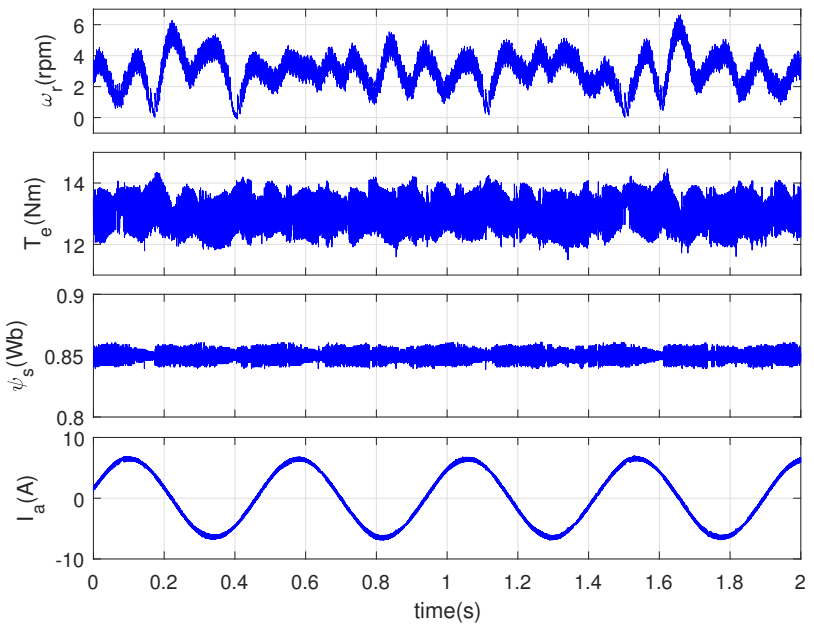

(b)

Fig. 14. Stead state operation at $3 \mathrm{r} / \mathrm{min}$ for UMV-MPC. (a) Without load and (b) with $90 \%$ rated load.

Electron., vol. 29, no. 12, pp. 6593-6603, 2014.

[12] F. Niu, B. Wang, A. S. Babel, K. Li, and E. G. Strangas, "Comparative evaluation of direct torque control strategies for permanent magnet synchronous machines," IEEE Trans. Power Electron., vol. 31, no. 2, pp. 1408-1424, Feb 2016.

[13] S. Kwak and S. k. Mun, "Model predictive control methods to reduce common-mode voltage for three-phase voltage source inverters," IEEE Trans. Power Electron., vol. 30, no. 9, pp. 5019-5035, Sept 2015.

[14] M. Habibullah, D. D. C. Lu, D. Xiao, and M. F. Rahman, "A simplified finite-state predictive direct torque control for induction motor drive," IEEE Trans. Ind. Electron., vol. 63, no. 6, pp. 3964-3975, June 2016.

[15] I. M. B. Hassine, M. W. Naouar, and N. Mrabet-Bellaaj, "Model predictive-sliding mode control for three-phase grid-connected converters," IEEE Trans. Ind. Electron., vol. 64, no. 2, pp. 1341-1349, Feb 2017.

[16] M. Preindl and S. Bolognani "Model predictive direct speed control with finite control set of pmsm drive systems," IEEE Trans. Power Electron., vol. 28 , no. 2, pp. $1007-1015$, feb. 2013.

[17] C. Xia, T. Liu, T. Shi, and Z. Song, "A simplified finite-controlset model-predictive control for power converters," IEEE Trans. Ind. Informat., vol. 10, no. 2, pp. 991-1002, 2014.

[18] W. Xie, X. Wang, F. Wang, W. Xu, R. M. Kennel, D. Gerling, and R. D. Lorenz, "Finite-control-set model predictive torque control with a deadbeat solution for pmsm drives," IEEE Transactions on Industrial Electronics, vol. 62, no. 9, pp. 5402-5410, Sept 2015.

[19] M. Nemec, D. Nedeljkovic, and V. Ambrozic, "Predictive torque control of induction machines using immediate flux control," IEEE Trans. Ind. Electron., vol. 54, no. 4, pp. 2009-2017, 2007.

[20] Y. Zhang, W. Xie, Z. Li, and Y. Zhang, "Low-complexity model predictive power control: Double-vector-based approach," IEEE Trans. Ind. Electron., vol. 61, no. 11, pp. 5871-5880, Nov 2014.

[21] J. Holtz, "The representation of ac machine dynamics by complex signal flow graphs," IEEE Trans. Ind. Electron., vol. 42, no. 3, pp. $263-271$, jun 1995.

[22] Y. Zhang, H. Yang, and B. Xia, "Model predictive torque control of induction motor drives with reduced torque ripple," IET Electr. Power Appl., vol. 9, no. 9, pp. 595-604, 2015.

[23] S. C. Chapra and R. P. Canale, Numerical methods for engineers, 6th ed. McGraw-Hill Higher Education, 2010.

[24] Y. Zhang, J. Zhu, Z. Zhao, W. Xu, and D. Dorrell, "An improved direct torque control for three-level inverter-fed induction motor sensorless drive," IEEE Trans. Power Electron., vol. 27, no. 3, pp. 1502 -1513, march 2012.

[25] Y. Zhang, H. Yang, and B. Xia, "Model-predictive control of induction motor drives: Torque control versus flux control," IEEE Trans. Ind Appl., vol. 52, no. 5, pp. 4050-4060, Sept 2016.

[26] K. Zhou and D. Wang, "Relationship between space-vector modulation and three-phase carrier-based PWM: a comprehensive analysis [threephase inverters]," IEEE Trans. Ind. Electron., vol. 49, no. 1, pp. 186-196, Feb. 2002.

[27] Y. Zhang and J. Zhu, "A novel duty cycle control strategy to reduce both torque and flux ripples for dtc of permanent magnet synchronous motor drives with switching frequency reduction," IEEE Trans. Power Electron., vol. 26, no. 10, pp. 3055 -3067, oct. 2011.

[28] — , "Direct torque control of permanent magnet synchronous motor with reduced torque ripple and commutation frequency," IEEE Trans. Power Electron., vol. 26, no. 1, pp. 235 -248, jan. 2011.

[29] K.-K. Shyu, J.-K. Lin, V.-T. Pham, M.-J. Yang, and T.-W. Wang, "Global minimum torque ripple design for direct torque control of induction motor drives," IEEE Trans. Ind. Electron., vol. 57, no. 9, pp. 31483156,2010

[30] Y. Zhang and H. Yang, "Torque ripple reduction of model predictive torque control of induction motor drives," in Energy Conversion Congress and Exposition (ECCE), 2013 IEEE, 2013, pp. 1176-1183.

[31] C. Rojas, J. Rodriguez, F. Villarroel, J. Espinoza, C. Silva, and M. Trincado, "Predictive torque and flux control without weighting factors," IEEE Trans. Ind. Electron., vol. 60, no. 2, pp. 681 -690, feb. 2013.

[32] Y. Zhang, H. Yang, and Z. Li, "A simple svm-based deadbeat direct torque control of induction motor drives," in 2013 International Conference on Electrical Machines and Systems (ICEMS), Oct 2013, pp. 2201-2206. 